\title{
Landscape Design in Aging Society Construction of Humanistic Care Consciousness
}

\author{
Chunsheng Xing
}

Institute of art and design, Huanghe Science and Technology College, Zhengzhou, China, 450063

xcshhkj@163.com

Keywords: Aging society, Humanities concern, Sustainable development of landscape

Abstract. With the rapid economic development, landscape architectural design also ushered in the development boom, as China entered the aging society development stage, part of the design began to realize humanistic care landscape architectural design ignored the aging background, from the people-centered design principles. Therefore, the importance of building material level design at the same times, also must pay attention to embody the spirit of humanity. This paper is based on this background, the analysis manifests the humanities concern consciousness building in landscape design, how to better in the city landscape design of humanistic care spirit made the quite comprehensive disc ussion, put forward related solutions, in order to make the city landscape design onto the scientific, healthy and sustainable development road.

\section{Introduction}

In the twenty-first Century, the rapid development of economy and Chinese, in the environment construction is also really set off a heat wave. Under this background, the landscape design planning also ushered in the growth of make a spurt of progress. But cannot be ignored, the aging society China has come, a lot of land scape design works gradually away from the "people-oriented, the principle of design based on environment", ignoring the humanistic thought building shows the problems in landscape design, ignore the problem of the aging society.

Humanistic care refers to a people in the spirit of humanity concern, care, specifically in the landscape towel is refers in the landscape design focus on creating a cultural atmosphere of. "The city is bigger, more people will feel lonely." This is a Latin proverb, it profoundly wrote a long residence in the people of modern city life experience. Loneliness is a great fear of creatures, humans are no exception. So, people need an emotional exchange place. As the city landscape design people recreation needs more emotional exchanges between people and people's care. Nowadays, with the aging era, people more the need to create a fusion of contemporary social morphology, cultural connotation, way of life, future oriented and user-friendly, multi comprehensive ideal living environment of space, this is a new era of given the responsibility and obligation to be one's unshirkable responsibility of land scape architects.

\section{The Necessity and Feasibility of B uilding the Humanities Concern in Landscape Design}

Humanistic care in landscape design is an important content of social welfare of city planning. Our country has entered the aging society, the aging of the population is currently increasing at the rate of 3\% annually, is expected in another 10 years, China's elderly population will account for the total population of $1 / 5$. This suggests, aging is one of the most serious problems in China in twentyfirst Century. So in the current economic conditions, how in the planning design and construction of garden, reflected on the elderly and care for the disabled, as far as possible to meet the basic requirements of their lives, is a research topic of current very urgent.

The elderly and disabled because of some characteristics of their own, the re are special require ments on the garden environment. First of all, they have weak physical, sensory recession, slow response and so on in life; secondly, there is a heavy human sentiment, heavy world, in the psychological situation requirements; at the same time also need the respect of others, stand on one's own desire demand. From the social perspective, their role and social economic status have also changed: in general by the leading into the auxiliary, from busy working time to rest into 
leisure time increased substantially, by taking social work mainly turn to community living etc.. These changes will bring them the psychological stress and emotional fluctuations, leading to the emergence of loneliness, sense of loss, impatience, inferiority and depression. Therefore, the elderly and disabled are pressing out of the home, a strong desire to close to the natural landscape environment, fresh air, sunshine, exercise, to communicate with people, mental and physical pleasure and actively participate in various community activities.

Needs in landscape design humane standard from the aged and disabled people's psychology and life, should be considered the social conditions and the different objects to give reasonable care. Judging from the current situation, the key problem is the detail processing structure of human consciousness problems of planning and design staff and the problems in the implementation process. Therefore, as long as we in the garden planning and design stage will consider this problem, should be no need to spend a lot of energy and financial resources, it can completely eliminate the tourism process for the elderly and disabled the inconvenience.

\section{Landscape Architecture Design to "Demand of Aging Population Analysis"}

Close to nature is the first psychological needs. Nowadays, the rapid urbanization since the thermal landscape of threat and destruction of growing, the natural landscape plays in people's daily life become more and more important role. The natural landscape can not only affect people's emotional, mental and physical health, but also to the degree of satisfaction with the impact on the environment and the physical environment of the people. The natural landscape has a positive role in alleviating psychological pressure and mental fatigue. There is a residential area more natural landscape, people will be more healthy and less plagued by health problems, lower incidence of psychotic disorders.

The city through the green corridor, river landscape, parks, urban wetlands, green street, unit garden greening landscape and residential area in the landscape, Roof garden, road greening landscape and natural landscape elements containing the Plaza, various types of natural landscape to provide more and better for people the opportunity to get close to nature.

Aesthetic is the purs uit of the spiritual life. People's pursuit of beauty has a long history, and the aesthetic is a preference, people prefer the natural landscape, in the city, more like is the main natural elements landscape, for example, park, street green, green channel, road green landscape, and the residential district green space are people like to stay and leisure place. Moreover, the beautiful landscape space can influence people's behavior and psychology, and be able to stimulate and promote mutual social intercourse. Aesthetic and preference to a large extent influe nce people to the city and the city landscape acceptance.

Social intercourse is the psychological expectations. Urban open space and natural landscape plays an important role in promoting the social intercourse between urban residents. Pleasant urban space and charming land scape can stimulate and facilitate social interactions, and can make the relationship between the residents of urban and more harmonious. The lack of available green space and social contacts will more likely to feel lonely, people face to face communication is also important to establish harmonious social relationships. The natural landscape to provide shade, privacy and protection from the surrounding environment noise, also can make people consume energy can be recovered and used these to attract people to the outdoor space to each other, so they have more opportunity to meet.

Exercise and demand is the development of human health considerations. People like to participate in various types of sports and leisure activities, for example, sitting, walking, jogging, cycling, games, travel, across age, gender, ethnic and socioeconomic backgrounds for sports and leisure needs. The space environment to the natural landscape and artificial landscape based, can meet the needs of people for sports and leisure activities, and in which the good experience. Therefore, parks, river landscape, green street, residential green space, science park open space and road green landscape, the children playground, sports and leisure entertainment can provide a good place for the people. 
The sense of belonging is eventually relying on landscape architecture design. At present, most of the residents of the city in the absence of their own city and residential identity and sense of belonging. There are many cause such factors, landscape characteristics of city environment is one of the factors. To meet the people's demand of city landscape pleasant environment, enhance the residents' sense of identity is effective support and sense of belonging.

Of our own history, familiar environment and humanistic tradition has very strong attachment and a sense of identity. Landscape design in the continuation of tradition of the humanities and history and undertake can effectively enhance the residents' sense of identity and belonging.

\section{Concept of Humanistic Care in the Garden}

The design principle of the garden space is designed to reflect the people-oriented.

Accessibility: refers to the garden environment should be free of obstacles and dangers. The elderly, the disabled due to changes in physiological and psychological conditions, demand and reality itself environment produce distance often, behavior and the environment of their contact will occur along with difficulty. That is to say, a normal person can use the normal things, to them it becomes an obstacle. Therefore, the sake of garden planning designers must place oneself in others' position for the old and infirm.

Legibility: refers to the identification and prompt set garden environment. The elderly, the disabled and prone to dangerous, this is because of their physical and mental incompetence or decline, resulting in danger sense ability failure. Therefore, the lack of space mark often will bring a range of discrimination, difficulty foreboding danger to them, bring on the behavior disorder and insecurity. To this end, we should make full use of visual, auditory and tactile means design, give the repeated prompts and inform. And through the spatial level and personality to create, space sequence, reasonable image feature shape distinctive logo and euphonious sound prompt, improve the orientation and identification of the landscape space.

Easy to reach: refers to the garden tours during the convenience and comfort. The elderly, the disabled action inconvenience, a return to the society and the desire to enjoy the physiological and psychological characteristics of green garden environment, which requires the garden site and its facilities with accessibility. Therefore, the designer should actively provide the possibility to participate in the all activities, from planning to ensure they from entrance to between the garden space at least a convenient, comfortable Wheelchair Access, and equipped with the necessary facilities, and ensure they have the physical effort to pay for the implementation of the psychological satisfaction.

There should be strict data requirements detail structure design in landscape architecture.

Entrance: width of at least 120 centimeters of above, elevation, slope should be controlled in a certain range, the ramp on both sides should add edges, and the use of anti-skid material. The entrance to a level around the space suitable for wheelchair users, in order to stay. In addition, the entrance as a plaque, the handwriting should make amblyopia can see, text and background color contrast strongly.

Road: road to slip, and as far as possible to the flat elevation, no bump, such as must set the height difference, should be $2 \mathrm{~cm}$ below. Width shall ensure that wheelchair users and pedestrian can wrong body through. In addition, should pay great attention to the use of Braille tile and guide sign setting, especially for the physically disabled persons cannot by the road, must have prior notice signs; not a safe place, in addition to set up risk markers, but also adding fence, guardrail armrest with Braille that best.

The ramp and step ramp: to help the elderly, disabled people to overcome the ground elevation, ensure the vertical mobile means, for the wheelchair to skid and gentle slope, slope length more than 10 meters, should be every 10 meters to set up a wheelchair rest platform. Step tread should be in $30-35 \mathrm{~cm}$ wide, high level should be 10 - 16 cent meters, the width of at least 1 meters, tread material should be non slip. Ramps and steps starting point, end point and turning should set the horizontal rest platform, and depending on the specific circumstances set armrest and night lighting. 
Green design in architectural design should highlight the needs of special populations. Psychological characteristics and physiological factors in the elderly, disabled people decide their demand for green space, garden than young and healthy people much more strongly. Land scape plants can purify air, adjust air temperature, dust and noise proof, very beneficial to elderly patients restore to health. Therefore, landscape design should first dominated by green, which in addition to landscape architecture, sketch, road, the other shall be covered with green plants. To make full use of vertical greening, through the formation of "ecological wall" to expand green space, improve the ecological environment, rich landscape. Secondly, in the treatment of the topography, to the extent possible, flat or slow corrosion v. In the choice of plants, to be suitable to planting trees, avoid planting prickly or root easily exposed plants, so as to avoid the formation of barrier. Again, in garden plant configuration, should suit one's measures to local conditions, scientific handling the relationship between mutual authentic between soft landscape trees, shrubs, flowers, inside the grass and garden architectural sketch. Let the elderly, the disabled in the visual, olfactory, tactile and physically feel full of garden plant landscape in different poses and with different expressions and rich ecological landscape and seasonal change of phase, stimulate their enthusiasm for life.

Building city landscape design in the design of street space outstanding safety and convenience. An important part of the street as the city space, along with the city's produce and form ", in the pre automobile age", the streets remained the pleasant space standards, the streets carrying function is also more comprehensive. Since the "cars", great changes have taken place in the city street, the street has the function to start gradually differentiation, expressway, pedestrian street, commercial street, began to appear. This paper attempts to put forward by Mr. Sadiff "cars" concept to explore the formation process of the city streets, to explore the design goal of city streets from the perspective of humanistic care.

\section{Summary}

Landscape architectural design is not from humanistic thought and existence, and embody the humanism thought in landscape architecture design is various, but the many aspects can be categorized into two major directions, one is the embodiment of humanistic culture, another is the embodiment of humanistic care, so whether it is in the actual design or appreciation of the landscape architecture, all from the two ways to reflect to the feelings of human thought, humanistic spirit.

\section{References}

[1] Liu Hao, The landscape design of the humanistic care of [J]; decoration; 200508.

[2] Xiao Xi, On the humanistic care of landscape design; art education "research", 201305. 